This item was submitted to Loughborough's Research Repository by the author.

Items in Figshare are protected by copyright, with all rights reserved, unless otherwise indicated.

\title{
Performance-based procedure for the definition of controlled low-strength mixtures
}

PLEASE CITE THE PUBLISHED VERSION

https://doi.org/10.1061/(ASCE)MT.1943-5533.0001283

PUBLISHER

(c) American Society of Civil Engineers (ASCE)

VERSION

AM (Accepted Manuscript)

LICENCE

CC BY-NC-ND 4.0

REPOSITORY RECORD

Pujadas, Pablo, Ana Blanco, Sergio H. Cavalaro, and Antonio Aguado. 2019. "Performance-based Procedure for the Definition of Controlled Low-strength Mixtures". figshare. https://hdl.handle.net/2134/32291. 
47 The controlled low-strength material (CLSM) is a cementitious material [1-5] made of binder, aggregates, water and admixtures. It is used as backfill in narrow trenches instead of compacted soil, in applications with strict requirements in terms of workability and mechanical strength.

For once, it should be highly fluid to allow the filling of tight and restricted areas in which placing and compaction would be otherwise difficult [2]. Nevertheless, it should not be excessively fluid so the material may keep in place in trenches with a slope. The CLSM must also have a minimum strength to endure the loads applied over the trench, without achieving excessively high values that compromise the reexcavation for repair and maintenance of the installation. Typically, a compressive strength of less than 8.3 $\mathrm{MPa}$ is needed, being higher than 2.0 MPa [1,3] in structural fills and between 0.7 and 1.4 MPa in backfill with small structural responsibility [1]. Although the achievement of such a small strength could seem trivial, the sustained accomplishment of low values within the tight range specified represents a challenge.

Limited information is available in the literature regarding mixture-proportioning methods for the definition of the CLSM based on the requirements of each application. The methods commonly used for similar materials like concrete do not apply given the particular composition and properties of CLSM. Alternatively, guidelines derived from experience or trial and error [4] are usually employed. Unfortunately, their generalization to any worksite is not feasible since the surrounding conditions and characteristics of components may differ from one place to another. The objective of this paper is to propose a rational mixture-proportioning approach to define the optimized CLSM composition depending on the requirements found in each 
worksite. For that, instead of computing the aggregate and the cement separately, all solid particles in the mixture are considered concurrently to estimate the water to solid ratio (W/S). This way the compressive strength can be modified without compromising the desired flowability. Then, an experimental program is conducted to validate this approach.

\section{NEW MIXTURE PROPORTIONING METHODOLOGY}

Fig. 1 depicts the performance-based methodology proposed for the optimal definition of CLSM mixtures, divided in steps that focus on the main requirements that the material should fulfil. The first step consists of achieving a solid system (S), constituted by aggregates (A) and a binder (B) with the highest packing density. The second step is to determine the water content needed to guarantee the desired workability. Finally, the third step consists of adjusting the binder content to obtain the adequate strength. An in depth description of each step is presented in the following sections.

Fig 1. Flowchart of the mixture proportioning of CLSM

\section{Step 1: Packing optimization}

The packing of the solid system has significant effect on the rheological and mechanical properties $[6,7]$ of CLSM. A higher packing tends to reduce the relative distance between particles, producing mixtures more stable in the fresh state, less prone to segregation and with higher compressive strength, thus reducing the cement consumption $[6,7]$. Therefore, identifying the highest packing is essential for the next steps, in which the workability and the mechanical properties are assessed. 
93 Since aggregates are the main components of the mixture (almost $80 \%$ of the total

94 volume), this step aims at finding the proportion of aggregates that gives the highest

95

$\phi=\frac{V_{S}}{V_{T}}$ packing in terms of solid concentration $(\phi)$. Such parameter is calculated with Eq. 1, taking $V_{T}$ as the total volume and $V_{S}$ as the volume of solids (binders + aggregates).

The wet packing test should be performed with several proportions of aggregates until the maximum packing $\left(\emptyset_{\max }\right)$ is obtained. Notice that the optimum contents of water and binder are not known at this stage. Since they should show small influence in the $\emptyset_{\max }$ obtained for the normal composition of CLSM, typical values are fixed in step 1.

\section{Step 2: Workability optimization}

The next step consists of determining the water demand to achieve the desired workability for the ideal solid system obtained in Step 1. Different authors have studied the physical roles of water in the fresh cementitious mixtures [8-12]. According to [11], the first of them is related with the absorption by the solid particles (Fig. 2a). The second role represents the minimum amount of water needed to involve and wet the surface of the solids (Fig. 2b). The third is to separate the solid grains and provide mobility (Fig. 2c), increasing the fluidity of the system.

\section{Fig.2. Physical roles of water in the fresh state}

In the CLSM, the water must fulfill these three roles for all solid components of the mixture. Nevertheless, given that the aggregate content is much bigger than that of binder, the influence of the former on the water needed and the resulting workability predominates. Hence, considering the typical composition, it makes more sense to use 
the water to aggregate ratio (W/A) rather than the water to binder ratio (W/B) used in concrete mixtures.

117 However, if only the W/A was considered, possible variations in the binder content 118 (Step 3) could lead to changes in the workability (Step 2), obligating new adjustments 119 of the water content. In other words, the definition of the mixture would need an iterative procedure with successive modifications of workability and strength.

A much more direct approach is possible by employing the water to solid ratio (W/S) as a reference parameter. Theoretically, by using the W/S as a reference, changes in the amount of binder would modify the aggregate content without affecting significantly the water content. Consequently, small changes in the amount of solid components should not compromise the workability of the mixture.

The W/S should be calculated through Eq. 1, in which $V_{W}$ is the water volume discounting what will be absorbed by the solid particles, $V_{A}$ is the aggregate volume and $V_{B}$ is the binder volume. Alternatively, this parameter may be calculated as a function of the contents of water $\left(C_{W}\right)$, aggregate $\left(C_{A}\right)$ and binder $\left(C_{B}\right)$ by weight, the total water absorption $(A)$ and the humidity $(H)$ of the aggregates, the densities of the water $\left(\gamma_{W}\right)$, of the aggregate $\left(\gamma_{A}\right)$ and of the binder $\left(\gamma_{B}\right)$.

$$
(W / S)=\frac{V_{W}}{V_{A}+V_{B}}=\frac{C_{W}+(H-A) \cdot C_{A}}{C_{A} \cdot \gamma_{B}+C_{B} \cdot \gamma_{A}} \cdot \frac{\gamma_{A} \cdot \gamma_{B}}{\gamma_{W}}
$$

132 For small W/S values, the water available is not enough to completely involve the solid particles. Consequently, changes in the W/S below the minimum required to wet the particles $\left((\mathrm{W} / \mathrm{S})_{\min }\right)$ produce almost no effect in the flow extent. Once the minimum wettability limit is surpassed, any extra amount of water added will increase the distance between particles and their mobility. As a result, higher values of W/S will lead to considerable increases in the workability. This effect reaches a saturation limit above 
which the addition of more water has small influence on the flow extent and may produce an unstable mixture prone to bleeding.

Several flow tests should be performed with different W/S until the optimum value that provides the required workability is found. A rough estimation of the minimum value required may be calculated through Eq. 2, obtained from [11]. Notice that $\emptyset_{\max }$ derived from Step 1 should be used.

$$
(W / S)_{\min }=0.90 \cdot\left(1-\emptyset_{\max }\right)
$$

\section{Step 3: Strength optimization}

Besides showing adequate flowability, the material should meet the strength requirements. The low-strength requirement of CLSM is necessary to allow the material re-excavability (based on [13], between $1.5 \mathrm{MPa}$ and $2.0 \mathrm{MPa}$ is suitable for most structural purposes).

In Step 3, the strength of the mixture is modified by changing the binder content until an optimum is achieved. In case of using Portland cement as binder, contents between 40 $\mathrm{kg} / \mathrm{m}^{3}$ and $100 \mathrm{~kg} / \mathrm{m}^{3}$ should be enough to achieve compressive strength ranging from $0.5 \mathrm{MPa}$ and 2.5 MPa.

To avoid affecting the optimum workability in this process, the proportion between aggregates obtained in Step 1 and the W/S derived from Step 2 are maintained constant in all trials. This means that, by changing the binder content, the amount of other materials in the mixture is also modified. The contents by weight of aggregate $\left(C_{A}\right)$ and of water $\left(C_{W}\right)$ are obtained for a certain content of binder $\left(C_{B}\right)$ according with Eq. 3 and 
4, respectively. In these equations, the ideal W/S derived from Step 2 should be used together with the estimated volume of voids of the mixture $\left(\mathrm{V}_{\mathrm{V}}\right)$.

$C_{A}=\left(\frac{1-V_{V}}{1+W / S}-\frac{C_{B}}{\gamma_{B}}\right) \cdot \gamma_{A}$

$C_{W}=\left(\frac{C_{A}}{\gamma_{A}}-\frac{C_{B}}{\gamma_{B}}\right) \cdot W / S$

\section{EXPERIMENTAL PROGRAM}

\section{Materials and mixing procedure}

All CLSM mixtures were produced with cement CEM II/A-M (V-L) 42.5R, which includes $11 \%$ of fly ash and $9 \%$ of limestone filler. The fine aggregates used were a limestone sand $0 / 2$ (with maximum nominal size of $2 \mathrm{~mm}$ ) and a limestone sand $0 / 4$ (with maximum nominal size of $4 \mathrm{~mm}$ ). Both of them have a solid particle density of $2.51 \mathrm{~g} / \mathrm{cm}^{3}$, showing absorption coefficients of $7.2 \%$ and $5.5 \%$, respectively. A polifuntional plasticizer (Pozzolith $475 \mathrm{~N}$ ) with a relative density of $1.20 \mathrm{~g} / \mathrm{cm}^{3}$ was added to some of the mixtures to evaluate its influence on the workability.

The CLSM were produced in a 5 liter mixer. First, the solid components and the water were mixed for 2 minutes. Then, the plasticizer - if used - was added and mixed for 2 additional minutes. Notice that aggregates were in saturated dry surface condition prior to the mixing process. This intends to mitigate the influence of the water absorption in the results.

177 The description of the experimental program and the results obtained follow the same sequence of phases defined for the mixture proportioning methodology. 
181

182

The wet packing test $[6,7,14]$ was performed in Step 1 to assess $\emptyset_{\max }$. The combinations of sand $0 / 2$ and sand $0 / 4$ by volume tested were $80 \%-20 \%, 65 \%-35 \%$, $50 \%-50 \%, 35 \%-65 \%$ and $20 \%-80 \%$. According with the methodology proposed here, the cement content was fixed at $40 \mathrm{~kg} / \mathrm{m}^{3}$ (equivalent to $12.91 / \mathrm{m}^{3}$ ) in all mixtures. Even though the water content should also be fixed, different W/S values were used with all combinations of aggregates to demonstrate some of the hypothesis assumed. In order to assess the influence of the plasticizer, mixtures from cases 1 to 5 were also produced with $1.5 \%$ of Pozzolith $475 \mathrm{~N}$ by weight of cement. These new compositions were designated as cases $1 \mathrm{P}$ to $5 \mathrm{P}$. Table 1 summarizes the different compositions studied.

\section{Table 1.. Compositions used for Steps 1 and 2.}

\section{Results and discussions}

Fig 3 presents the results of the wet packing test for different proportions of aggregates. For the present study, the proportion that gives $\emptyset_{\max }$ includes $50 \%$ of aggregate $0 / 2$ and $50 \%$ of aggregate $0 / 4$. The same is observed regardless whether the W/S chosen is 0.30 , 0.35 or 0.45 . This confirms that the W/S may be fixed in Step 1 within the typical range used in CLSM, without significantly compromising the assessment of the proportion of aggregates that provides the maximum packing.

Fig.3. Variation of $\emptyset$ with different aggregate combinations for typical W/S.

The dotted curves in Fig. 3 correspond to the mixtures with plasticizer, which show practically the same results as those of equivalent compositions without plasticizer. This suggests that the plasticizer has no influence in the optimum proportion estimated or the packing for the W/S tested. 
Step 2: Workability optimization

\section{Mixture composition and test procedure}

207 In Step 2, the workability of mixtures with different W/S and the proportion of 208 aggregates that yield $\emptyset_{\max }$ in Step 1 should be assessed to derive the optimum W/S. Nonetheless, to evaluate some of the hypotheses of the method, tests were conducted with all aggregate proportions considered in Step 1. Therefore, the same mixture compositions from Table 1 were used to study the optimization of the workability, which was evaluated through the measurement of the diameter of the flow extent according with test from EN 1015-3 [15].

Results and discussions

According to [1], mixtures may be classified as with low (for diameters smaller than $150 \mathrm{~mm}$ ), with normal (between 150 to $200 \mathrm{~mm}$ ) and with high flowability (bigger than $200 \mathrm{~mm}$ ). Fig.4 depicts the average diameter of the flow extent for different values of $\mathrm{W} / \mathrm{S}$. The continuous and the dotted curves indicate the measurements from mixtures without and with the plasticizer, respectively.

222 A minimum influence of the plasticizer on the consistency of the CLSM is evident in 223 the results. The low effectiveness of the plasticizer may be attributed to the low content 224 of cement used in CLSM and the high water/cement ratio used. In conventional concrete, the plasticizer molecules distribute around cement particles and avoid their agglomeration, increasing the plasticity of the mixture. In the case of CLSM, since low 
contents of cement are used, this effect is diminished as few of the solid particles that constitute the mixture are being dispersed. Moreover, the high amount of water reduces the likelihood of cement particle interaction and agglomeration.

An S shaped curve is obtained in almost all cases. These curves present an initial stretch for low W/S in which the amount of water available is not enough to provide the mixture with plasticity. Notice that the (W/S $)_{\min }$ calculated according with Eq. 3 ranges from 0.25 and 0.30 for the $\emptyset_{\max }$ estimated in Step 1. This agrees with the curves from Fig. 6 that show small variation of the flow extent for mixtures with W/S smaller than 0.3 .

For values of W/S bigger than such limit, all curves show a pronounced increase of the workability. This indicates that the amount of water available is enough to wet the solid particles and to separate them, increasing their mobility. As the W/S approaches 0.45 , the rate of increase of the flow extent decreases. This suggests that the mixture enters a saturation stage in which the increase in the water content has small influence in the mobility of the particles, increasing the risk of bleeding. An optimum W/S of 0.37 was selected based on the results from Fig. 4.

\section{Step 3: Optimization of the cement content}

Mixture composition and test procedure

In Step 3, the cement content that provides the desired compressive strength is determined by using compositions with the optimum aggregate proportion and W/S

247 derived from Steps 1 and 2, respectively. As shown in Table 2, CLSM with cement 248 contents ranging from 40 to $85 \mathrm{~kg} / \mathrm{m}^{3}$ (comp. 4 to 8 ) were produced. For economic reasons, the aggregate system was defined as $35 \%$ of sand $0 / 2$ and $65 \%$ of sand $0 / 4$. 
251 evaluate the influence of the admixture on the compressive strength. These are

252

253

254

256

257

258

259

260

261

262

263

264

265

266

267

268

269

270

271

272

273 analogous to compositions 4 and 8 .

Table 2. Mixture composition for the optimization of cement content.

Specimens with $4 \mathrm{~cm} \times 4 \mathrm{~cm} \times 16 \mathrm{~cm}$ were cast, stored in a climate-controlled room at $20{ }^{\circ} \mathrm{C}$ and a relative humidity of $50 \%$ and tested for the compressive strength in accordance with EN 196-1. The results were determined as the average of 6 measurements. Although this is not required in the mixture proportioning methodology proposed here, the wet packing test and the flow extent were performed again with all compositions from Table 2. The aim is to demonstrate that the succession of steps defined and the philosophy based on the W/S yields the optimum composition without the need for iterative adjustments of parameters. For that, it is necessary to prove that variations in the cement content in Step 3 do not affect the packing and the flow extent derived from Steps 1 and 2.

\section{Results and discussions}

Fig. 5 presents the compressive strength measured at 1, 7 and 28 days for compositions 4 to 8 . The results show that the increase of the cement content produces an increase of the compressive strength. Despite that, the measurements reveal an interesting phenomenon regarding the evolution of strength with time. Interestingly, the results from the tests at 1 and 7 days are bigger than those at 28 days. Similar strength loss was reported by [30] due to the evolution of the humidity during the curing process combined with the special composition of the CLSM mixtures.

Fig.5. Compressive strength for different cement contents. 
274 The evolution of the compressive strength over time is a consequence of the sum of two

275 phenomenon. On one hand, the hydration of the cement with time should increase the

276 strength of the connection between particles. On the other hand, the water present in the

277 form of humidity in the pores creates suction forces that act at the contact between

278 particles, pulling them together. Such forces produce a confining pressure for

279 unsaturated conditions similarly to the observed in certain soils, contributing to an

280 increase of the compressive strength of the CLSM.

281 The CLSM may suffer a drying process with time. Part of the water is evaporated and

282 part is consumed by the cement hydration. Although the latter contributes to increase

283 the compressive strength, the drying process diminishes the humidity in the pores and

284 reduces the contribution of the suction effect, reducing the compressive strength. Once

285 the humidity of the sample is in balance with the environment, no more strength loss is

286 expected. Considering that this balance was already reached for 28 days, a cement

287 content of $70 \mathrm{~kg} / \mathrm{m}^{3}$ was selected as adequate since it provides compressive strengths

288 within the range established originally (from 1 to $2 \mathrm{MPa}$ ). Therefore, the ideal CLSM

289 for the case study is represented by the composition 7 from Table 2.

290 To show the influence of the drying process, an additional set of specimens from

291 composition 8 were stores stored at $20{ }^{\circ} \mathrm{C}$ and $98 \%$ of relative humidity, thus limiting

292 the loss of moisture from the CLSM. Under these conditions, the compressive

293 strengthes measured at 1, 7 and 28 days were 1.9, 1,9 and 2.1 MPa, respectively. Even

294 though the increase is minor, notice that no significant reduction occurs at 28 days.

295 Such results confirm the influence of the drying process in the compressive strength.

296 This should be considered when defining the curing conditions for the specimens, which

297 should be representative of the expected in reality. 
Fig. 6 depicts the results of the wet packing and flow extent test for the cement contents considered (cases 4, 6, 7, 8, 4P and 8P). Notice that, despite increasing the cement content, the values of solid concentration, void ratio and flow diameter remain approximately constant, thus validating the approach proposed here. In fact, the sequence of steps defined and the philosophy based on the definition of a W/S allows the direct assessment of the optimum composition of the CLSM. Once more, equivalen compositions with plasticizer and without plasticizer show approximately the same behavior.

Fig. 6. Comparison of wet packing and flow extent for different cement contents, with and without plasticizer.

\section{CONCLUSIONS}

A methodology for the optimal mixture proportioning of CLSM was proposed based on the main requirements of each application and without the need of interactive adjustments of the composition. This methodology represents a contribution towards the definition of the CLSM, minimizing the consumption of cement and of admixtures. Future research should be performed to enlarge the scope of application of the methodology including other types of components as recycled aggregates or mineral admixtures.

The following conclusions are derived from this study.

- The W/S should be used as a reference parameter in the definition of the CLSM composition. This provides flexibility to the procedure since the composition may be modified without compromising the optimum workability. 
- The definition of the W/S required must consider the roles of water in the mixture (absorption by the aggregates, wetting of the surface of the grains and increase of mobility). The results obtained with the formulation proposed to estimate the minimum $\mathrm{W} / \mathrm{S}$ agrees with the experimental results. In fact, compositions with W/S below the minimum present deficient workability.

- The plasticizer has no evident repercussion on the packing, the workability or the compressive strength of CLSM. This is attributed to the high amount of water and low content of cement in typical CLSM, both of which reduce the need for this type of admixture.

\section{Acknowledgment}

The authors thank the company Gas Natural Fenosa for the financial support and, in particular, for its active collaboration in the project. Likewise, the authors appreciate the comments of Jordi Roselló and Carlos Aranda. The first author acknowledges the grant PDJ provided Departament d'Universitats, Recerca i Societat de la Informació de la Generalitat de Catalunya.

\section{References}

[1] ACI Committee 229. Controlled low-strength materials (ACI 229R-99). Farmington Hills (MI): American Concrete Institute; 1999.

[2] Siddique R. Utilisation of waste materials and by-products in producing controlled low-strengght materials. Resour Conserv Recy 2009; 54: 1-8

[3] Alizadeh, V.; Helwany, S.; Ghorbanpoor, A. and Sobolev, K. (2014) Design and application of controlled low strength materials as a structural fill, Construction and Building Materials, 53, pp. 425-431

[4] Bouzalakos, S.; Dudeney, A.W.L. and Chan, B.K.C. (2013) Formulating and optimising the compressive strength of controlled low-strength materials containing mine tailings by mixture design and response surface methods, Minerals Engineering, Volume 53, November 2013, Pages 48-56

[5] Etxebarria M, Ainchil J, Pérez ME, González A. (2013) Use of recycled fine aggregates for Control Low Strength Materials (CLSMs) production. Constr Build Mater; 44:142-148.

[6] A.K.H. Kwan, W.W.S. Fung. Packing density measurement and modelling of fine aggregate and mortar. Cement \& Concrete Composites 31 (2009) 349-357 Contents 
[7] Fung, W. W. S. A. K. H. Kwan and H. H. C. Wong. Wet packing of crushed rock fine aggregate. Materials and Structures (2009) 42:631-643

[8] Fung, W. W. S., \& Kwan, a. K. H. (2010). Role of water film thickness in rheology of CSF mortar. Cement and Concrete Composites, 32(4), 255-264.

[9] Kwan, a. K. H. \& Fung, W. W. S. (2012). Roles of water film thickness and SP dosage in rheology and cohesiveness of mortar. Cement \& Concrete Composites 34 (2) $121-130$

[10] Fennis, S.A.A.M. (2011). Design of Ecological Concrete by Particle Packing Optimization. PhD Thesis, Delft: Delft University of Technology.

[11] Klein N. (2012) El Rol físico del agua en mezclas de cemento Portland, Doctoral Thesis, Universitat Politècnica de Catalunya, Barcelona.

[12] Klein, N.S.; Bachmann, J. ; Aguado, A. and Toralles-Carbonari, B. (2012) Evaluation of the wettability of mortar component granular materials through contact angle measurements, Cement and Concrete Research, 42(12), pp. 16111620

[13] Blanco, A., Pujadas, P., Cavalaro, S.H.P., Aguado, A. Methodology for the design of controlled low-strength materials. Application to the backfill of narrow renches (2014) Construction and Building Materials, 72, pp. 23-30.

[14] Wong, H. H. C., \& Kwan, A. K. H. (2007). Packing density of cementitious materials: part 1-measurement using a wet packing method. Materials and Structures, 41(4), 689-701.

[15] ASTM C1437 (2003) Standard Test Method for Flow of Hydraulic Cement Mortar. ASTM International, West Conshohocken, PA, DOI: 10.1520/C1437 
Table 1. Compositions used for Steps 1 and 2.

\begin{tabular}{|c|c|c|c|c|c|c|c|c|c|c|c|}
\hline$W / S$ & {$[-]$} & 0.25 & 0.30 & 0.35 & 0.40 & 0.45 & 0.25 & 0.30 & 0.35 & 0.40 & 0.45 \\
\hline & & \multicolumn{5}{|c|}{ Comp. 1: 80\%-20\% } & \multicolumn{5}{|c|}{ Comp. 1P: 80\%-20\% } \\
\hline Cement & $\left(\mathrm{kg} / \mathrm{m}^{3}\right)$ & 40 & 40 & 40 & 40 & 40 & 40 & 40 & 40 & 40 & 40 \\
\hline Sand $0 / 2$ & $\left(\mathrm{~kg} / \mathrm{m}^{3}\right)$ & 1580 & 1518 & 1461 & 1408 & 1358 & 1580 & 1518 & 1461 & 1408 & 1358 \\
\hline Sand $0 / 4$ & $\left(\mathrm{~kg} / \mathrm{m}^{3}\right)$ & 397 & 381 & 367 & 353 & 341 & 397 & 381 & 367 & 353 & 341 \\
\hline Water & $\left(\mathrm{kg} / \mathrm{m}^{3}\right)$ & 200 & 231 & 259 & 286 & 310 & 200 & 231 & 259 & 286 & 310 \\
\hline \multirow[t]{2}{*}{ Plasticizer } & $(\%)$ & - & - & - & - & - & 1.5 & 1.5 & 1.5 & 1.5 & 1.5 \\
\hline & & \multicolumn{5}{|c|}{ Comp. 2: 65\%-35\% } & \multicolumn{5}{|c|}{ Comp. 2P: $65 \%-35 \%$} \\
\hline Cement & $\left(\mathrm{kg} / \mathrm{m}^{3}\right)$ & 40 & 40 & 40 & 40 & 40 & 40 & 40 & 40 & 40 & 40 \\
\hline Sand $0 / 2$ & $\left(\mathrm{~kg} / \mathrm{m}^{3}\right)$ & 1283 & 1233 & 1187 & 1144 & 1103 & 1283 & 1233 & 1187 & 1144 & 1103 \\
\hline Sand $0 / 4$ & $\left(\mathrm{~kg} / \mathrm{m}^{3}\right)$ & 694 & 667 & 642 & 618 & 597 & 694 & 667 & 642 & 618 & 597 \\
\hline Water & $\left(\mathrm{kg} / \mathrm{m}^{3}\right)$ & 200 & 231 & 259 & 286 & 310 & 200 & 231 & 259 & 286 & 310 \\
\hline \multirow[t]{2}{*}{ Plasticizer } & $(\%)$ & - & - & - & - & - & 1.5 & 1.5 & 1.5 & 1.5 & 1.5 \\
\hline & & \multicolumn{5}{|c|}{ Comp. 3: 50\%-50\% } & \multicolumn{5}{|c|}{ Comp. 3P: 50\%-50\% } \\
\hline Cement & $\left(\mathrm{kg} / \mathrm{m}^{3}\right)$ & 40 & 40 & 40 & 40 & 40 & 40 & 40 & 40 & 40 & 40 \\
\hline Sand $0 / 2$ & $\left(\mathrm{~kg} / \mathrm{m}^{3}\right)$ & 987 & 949 & 913 & 880 & 849 & 987 & 949 & 913 & 880 & 849 \\
\hline Sand $0 / 4$ & $\left(\mathrm{~kg} / \mathrm{m}^{3}\right)$ & 991 & 952 & 916 & 883 & 852 & 991 & 952 & 916 & 883 & 852 \\
\hline Water & $\left(\mathrm{kg} / \mathrm{m}^{3}\right)$ & 200 & 231 & 259 & 286 & 310 & 200 & 231 & 259 & 286 & 310 \\
\hline \multirow[t]{2}{*}{ Plasticizer } & $(\%)$ & - & - & - & - & - & 1.5 & 1.5 & 1.5 & 1.5 & 1.5 \\
\hline & & \multicolumn{5}{|c|}{ Comp. 4: 35\%-65\% } & \multicolumn{5}{|c|}{ Comp. 4P: 35\%-65\% } \\
\hline Cement & $\left(\mathrm{kg} / \mathrm{m}^{3}\right)$ & 40 & 40 & 40 & 40 & 40 & 40 & 40 & 40 & 40 & 40 \\
\hline Sand $0 / 2$ & $\left(\mathrm{~kg} / \mathrm{m}^{3}\right)$ & 691 & 664 & 639 & 616 & 594 & 691 & 664 & 639 & 616 & 594 \\
\hline Sand $0 / 4$ & $\left(\mathrm{~kg} / \mathrm{m}^{3}\right)$ & 1289 & 1238 & 1192 & 1148 & 1107 & 1289 & 1238 & 1192 & 1148 & 1107 \\
\hline Water & $\left(\mathrm{kg} / \mathrm{m}^{3}\right)$ & 200 & 231 & 259 & 286 & 310 & 200 & 231 & 259 & 286 & 310 \\
\hline \multirow[t]{2}{*}{ Plasticizer } & $(\%)$ & - & - & - & - & - & 1.5 & 1.5 & 1.5 & 1.5 & 1.5 \\
\hline & & \multicolumn{5}{|c|}{ Comp. 5: 20\%-80\% } & \multicolumn{5}{|c|}{ 5P: $20 \%-80 \%$} \\
\hline Cement & $\left(\mathrm{kg} / \mathrm{m}^{3}\right)$ & 40 & 40 & 40 & 40 & 40 & 40 & 40 & 40 & 40 & 40 \\
\hline Sand $0 / 2$ & $\left(\mathrm{~kg} / \mathrm{m}^{3}\right)$ & 395 & 380 & 365 & 352 & 340 & 395 & 380 & 365 & 352 & 340 \\
\hline Sand $0 / 4$ & $\left(\mathrm{~kg} / \mathrm{m}^{3}\right)$ & 1586 & 1524 & 1467 & 1413 & 1364 & 1586 & 1524 & 1467 & 1413 & 1364 \\
\hline Water & $\left(\mathrm{kg} / \mathrm{m}^{3}\right)$ & 200 & 231 & 259 & 286 & 310 & 200 & 231 & 259 & 286 & 310 \\
\hline Plasticizer & $(\%)$ & - & - & - & - & - & 1.5 & 1.5 & 1.5 & 1.5 & 1.5 \\
\hline
\end{tabular}

Table 2. Mixture composition for the optimization of cement content.

\begin{tabular}{lc|cccccc}
\hline \multicolumn{2}{c|}{ Materials } & \multicolumn{7}{c}{ Quantities } \\
\hline \multicolumn{2}{c}{ Comp. } & $\mathbf{4}$ & $\mathbf{6}$ & $\mathbf{7}$ & $\mathbf{8}$ & 4P & $\mathbf{8 P}$ \\
\hline Cement & $\left(\mathrm{kg} / \mathrm{m}^{3}\right)$ & 40 & 55 & 70 & 85 & 40 & 85 \\
Sand 0/2 & $\left(\mathrm{kg} / \mathrm{m}^{3}\right)$ & 691 & 611 & 607 & 603 & 691 & 603 \\
Sand 0/4 & $\left(\mathrm{kg} / \mathrm{m}^{3}\right)$ & 1287 & 1140 & 1132 & 1124 & 1287 & 1124 \\
Water & $\left(\mathrm{kg} / \mathrm{m}^{3}\right)$ & 286 & 286 & 286 & 286 & 286 & 286 \\
Plasticizer & $(\%)$ & - & - & - & - & 1.5 & 1.5 \\
\hline
\end{tabular}




\section{Figure}

Click here to download Figure: TN_asce_TN_fig 1.pdf

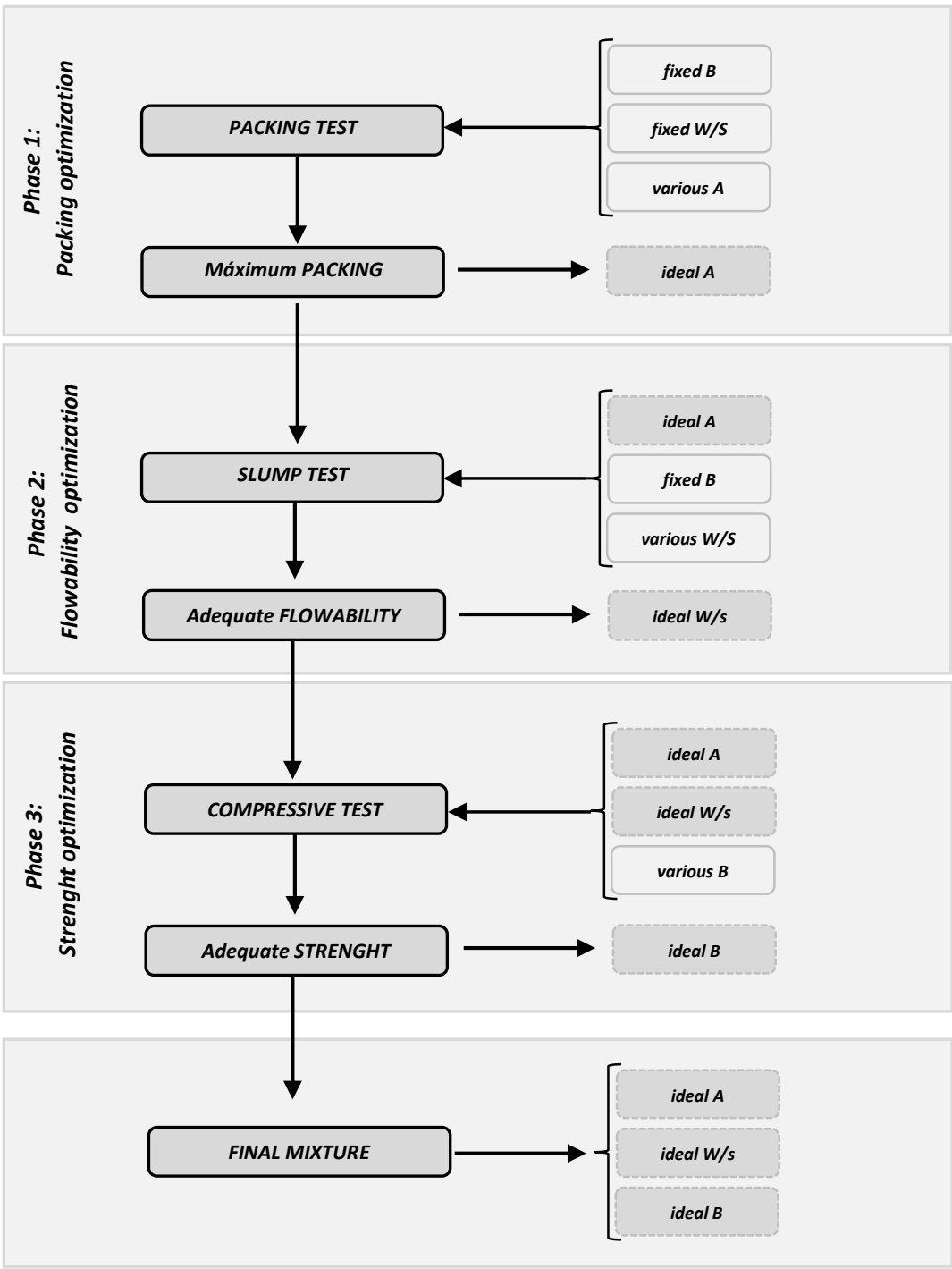


a)

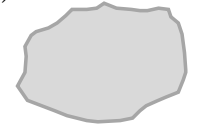

b)

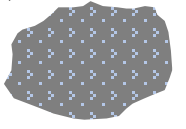

c)

d)

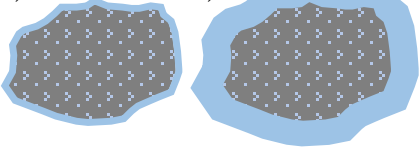




\section{Figure}

Click here to download Figure: TN_asce_TN_fig 3.pdf
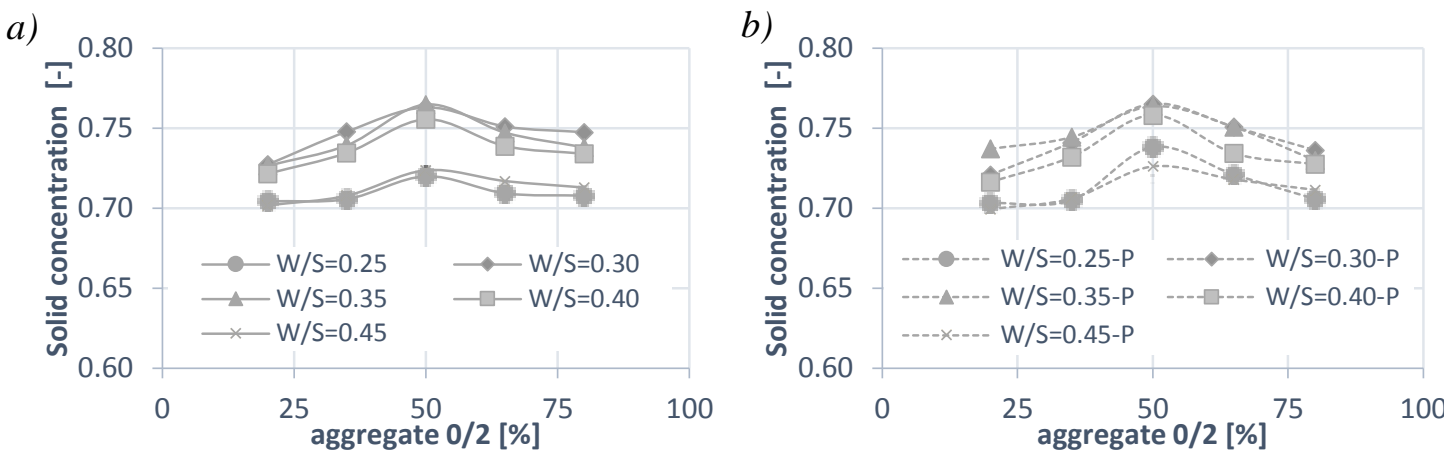
a) Comp. 1 and 1P: 80-20

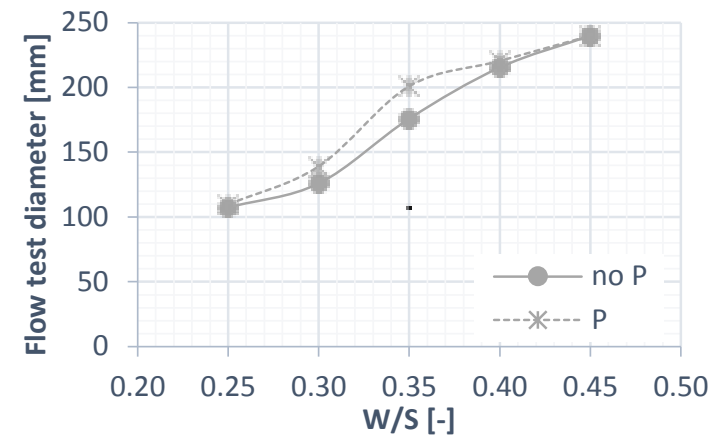

b) Comp. 2 and 2P: 65-35

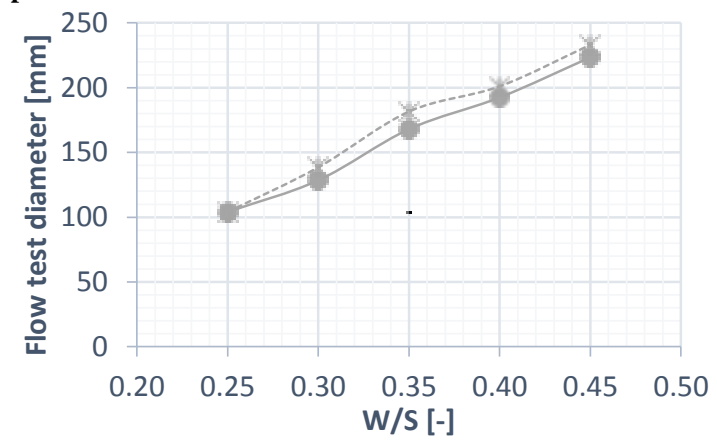

c) Comp. 3 and 3P: 50-50

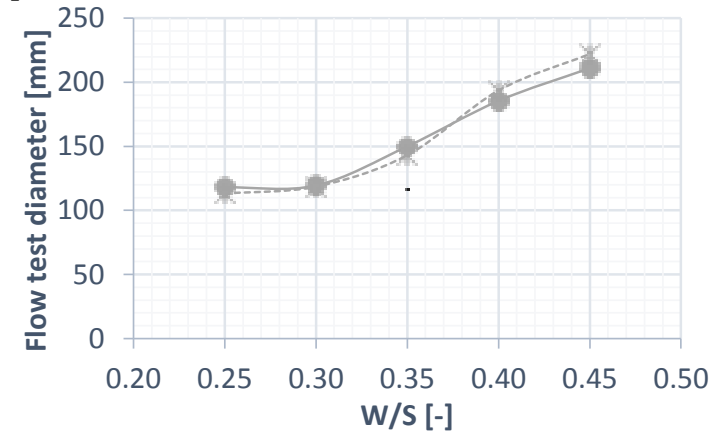

d)

\section{Comp. 4 and 4P: 35-65}

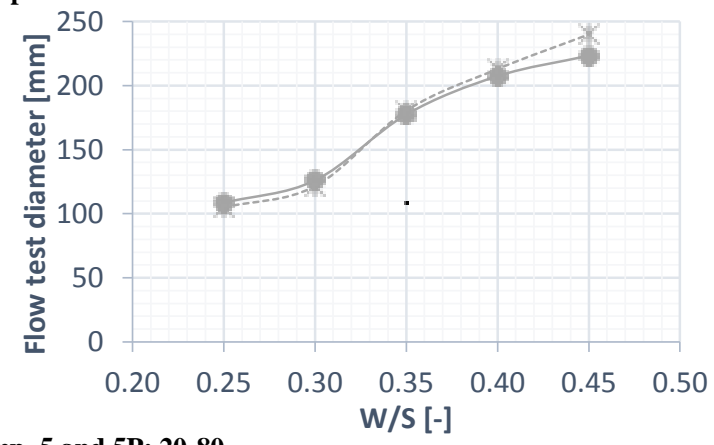

e)

Comp. 5 and 5P: 20-80

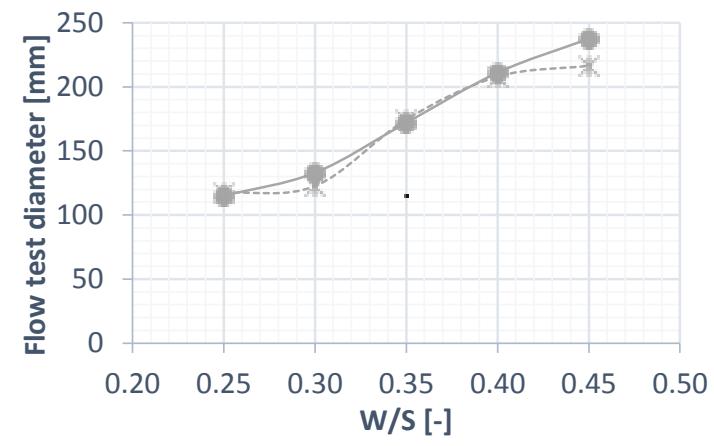


Click here to download Figure: TN_asce_TN_fig 5.pdf

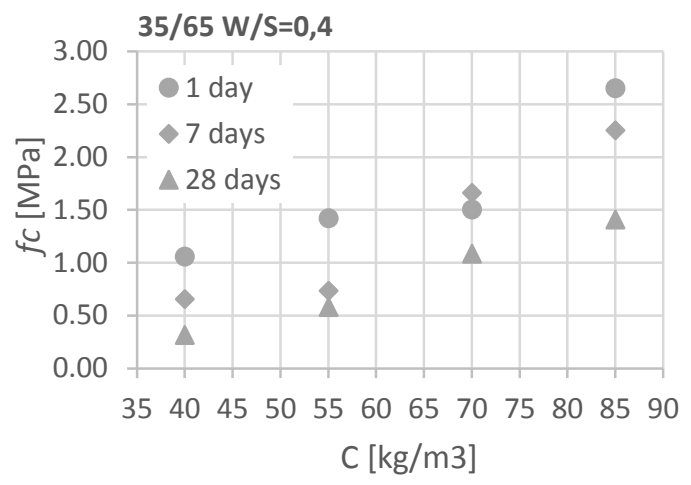

$\mathrm{C}[\mathrm{kg} / \mathrm{m} 3]$ 
Click here to download Figure: TN_asce_TN_fig 6.pdf
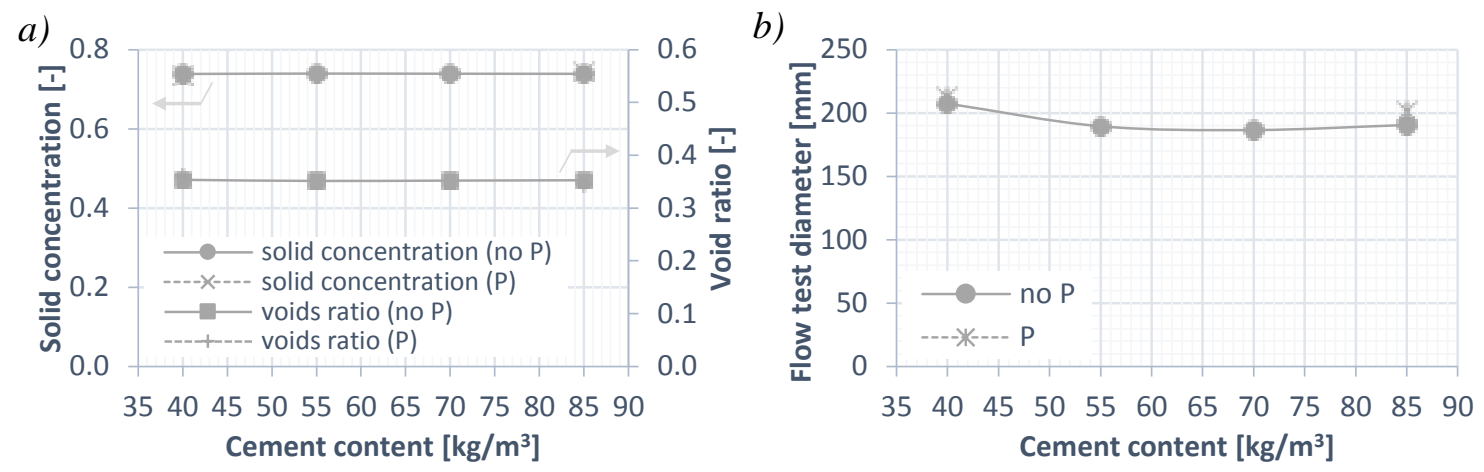